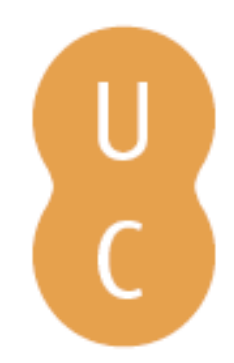

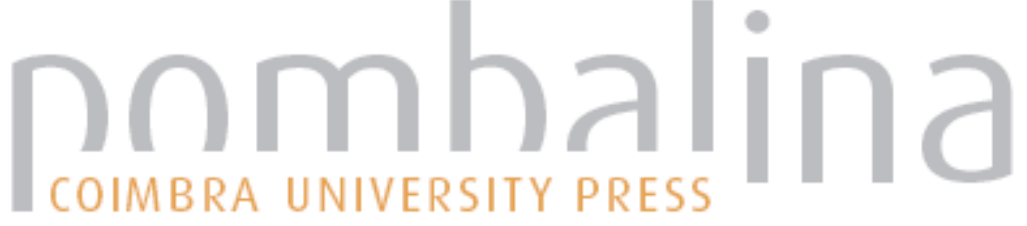

\section{As oficinas de Muhipiti e a Unilúrio}

\author{
Autor(es): Noa, Francisco \\ Publicado por: Imprensa da Universidade de Coimbra \\ URL \\ persistente: URI:http://hdl.handle.net/10316.2/44307 \\ DOI: $\quad$ DOl:https://doi.org/10.14195/978-989-26-1556-1_2
}

Accessed : $\quad$ 26-Apr-2023 12:05:06

A navegação consulta e descarregamento dos títulos inseridos nas Bibliotecas Digitais UC Digitalis, UC Pombalina e UC Impactum, pressupõem a aceitação plena e sem reservas dos Termos e Condições de Uso destas Bibliotecas Digitais, disponíveis em https://digitalis.uc.pt/pt-pt/termos.

Conforme exposto nos referidos Termos e Condições de Uso, o descarregamento de títulos de acesso restrito requer uma licença válida de autorização devendo o utilizador aceder ao(s) documento(s) a partir de um endereço de IP da instituição detentora da supramencionada licença.

Ao utilizador é apenas permitido o descarregamento para uso pessoal, pelo que o emprego do(s) título(s) descarregado(s) para outro fim, designadamente comercial, carece de autorização do respetivo autor ou editor da obra.

Na medida em que todas as obras da UC Digitalis se encontram protegidas pelo Código do Direito de Autor e Direitos Conexos e demais legislação aplicável, toda a cópia, parcial ou total, deste documento, nos casos em que é legalmente admitida, deverá conter ou fazer-se acompanhar por este aviso.

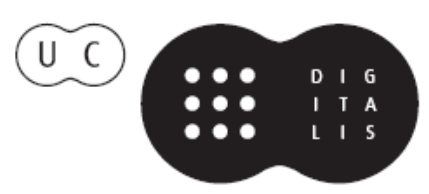




\section{OFICINAS DE \\ MUHIPITI \\ planeamento estratégico \\ património \\ desenvolvimento}

organização:

Walter Rossa

Nuno Lopes

Nuno Simão Gonçalves

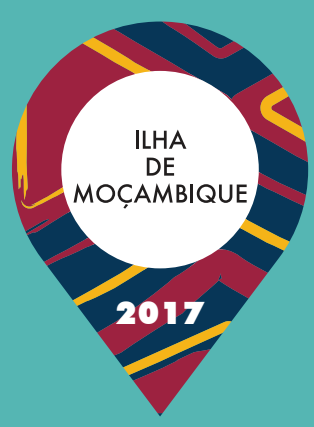




\section{AS OFICINAS DE MUHIPITI E A UNILÚRIO}

Francisco Noa

Reitor da Universidade Lúrio

Isequiel Alcolete

Diretor da Faculdade de Arquitetura e Planeamento Físico da Universidade Lúrio

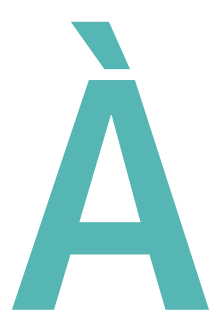

luz da missão da Universidade Lúrio [UniLúrio], "Educar e formar uma nova geração de profissionais competentes, comprometidos com a ciência, o desenvolvimento e o bem-estar das comunidades locais", o Magnífico Reitor da UniLúrio, Francisco Pedro dos Santos Noa, lançou o desafio aos coordenadores do projeto e curso de doutoramento em Patrimónios de Influência Portuguesa [PIP] do Instituto de Investigação Interdisciplinar e Centro de Estudos Sociais da Universidade de Coimbra [UC] para, em conjunto com a Faculdade de Arquitetura e Planeamento Físico da UniLúrio [FAPF], equacionar modelos de otimização do impacto catalisado pela instalação da Faculdade de Ciências Sociais e Humanas [FCSH] e do Centro de Estudos de Documentação da Ilha de Moçambique [CEDIM] da UniLúrio na llha de Moçambique.

A UniLúrio tem profunda e clara consciência da sua inserção e responsabilidade na Ilha de Moçambique, nesta designada era da globalização. Nela, a política e, sobretudo, a gestão ligada à cultura e, em particular, ao património, determinam e gerem âmbitos que têm a peculiaridade de cativar interesse mundial. A valorização crescente do património cultural e natural em Moçambique, no geral, e na llha, em particular, com a inscrição desta, em 1991, na Lista do Património Mundial da UNESCO, acentua a inserção do país nos caminhos da 
globalização. Fica cada vez mais claro que, tal como as políticas, a economia e o património Ihe estão ligados, é necessário que o ensino também esteja. Uma primeira adaptação do ensino superior a essa necessidade torna-se necessária para construir uma nova atitude nos âmbitos da investigação e inovação, fomentando parcerias qualificadas com a sociedade, as indústrias, as empresas, os centros tecnológicos e as instituições gestoras e culturais.

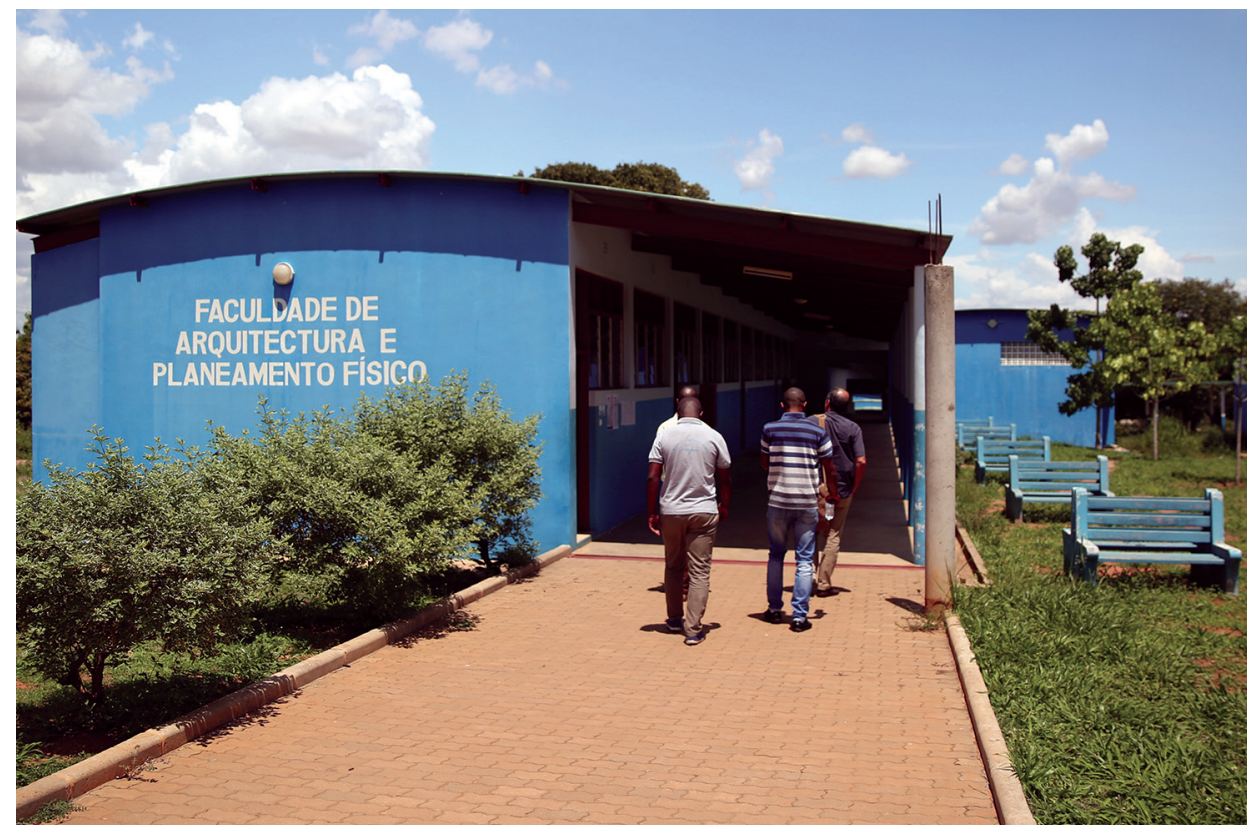

Este modelo pretende integrar igualmente a mobilidade dos alunos e dos docentes, favorecendo a empregabilidade e soluções no mercado alargado, tanto moçambicano como do resto do mundo, através da prática no processo de investigação. O aprofundamento da investigação aplicada em temas específicos relacionados com o património, implica que se definam conteúdos diversificados e transversais em vários domínios do saber científico. Conhecimentos e aprofundamentos que devem ser aplicados nas propostas de intervenções em formas metodologicamente certas e exequíveis.

As condições atuais da Ilha, as estruturas institucionais e legais, as condições socioeconómicas e mesmo a presente fase do 
desenvolvimento, justificam a produção frequente de eventos práticos com conteúdos relacionados com o património, conferindo, portanto, intervenções com competência e responsabilidade.

A adoção de métodos alternativos de aprendizagem e intervenção centrados no intercâmbio e mobilidade de estudantes, professores e investigadores, por via da participação em programas de pós-graduação e workshops, está a ser implementado entre as Universidades Lúrio e de Coimbra, de modo a tornar o processo de ensino capaz de apresentar soluções materializáveis na área de intervenção. Tais métodos vão ao encontro da real filosofia de mobilidade e internacionalização da Unilúrio, dos docentes e discentes. A UniLúrio adotou, desde o seu início, métodos de ensino e aprendizagem em que ao estudante é colocado o desafio de ser responsável na busca de soluções.

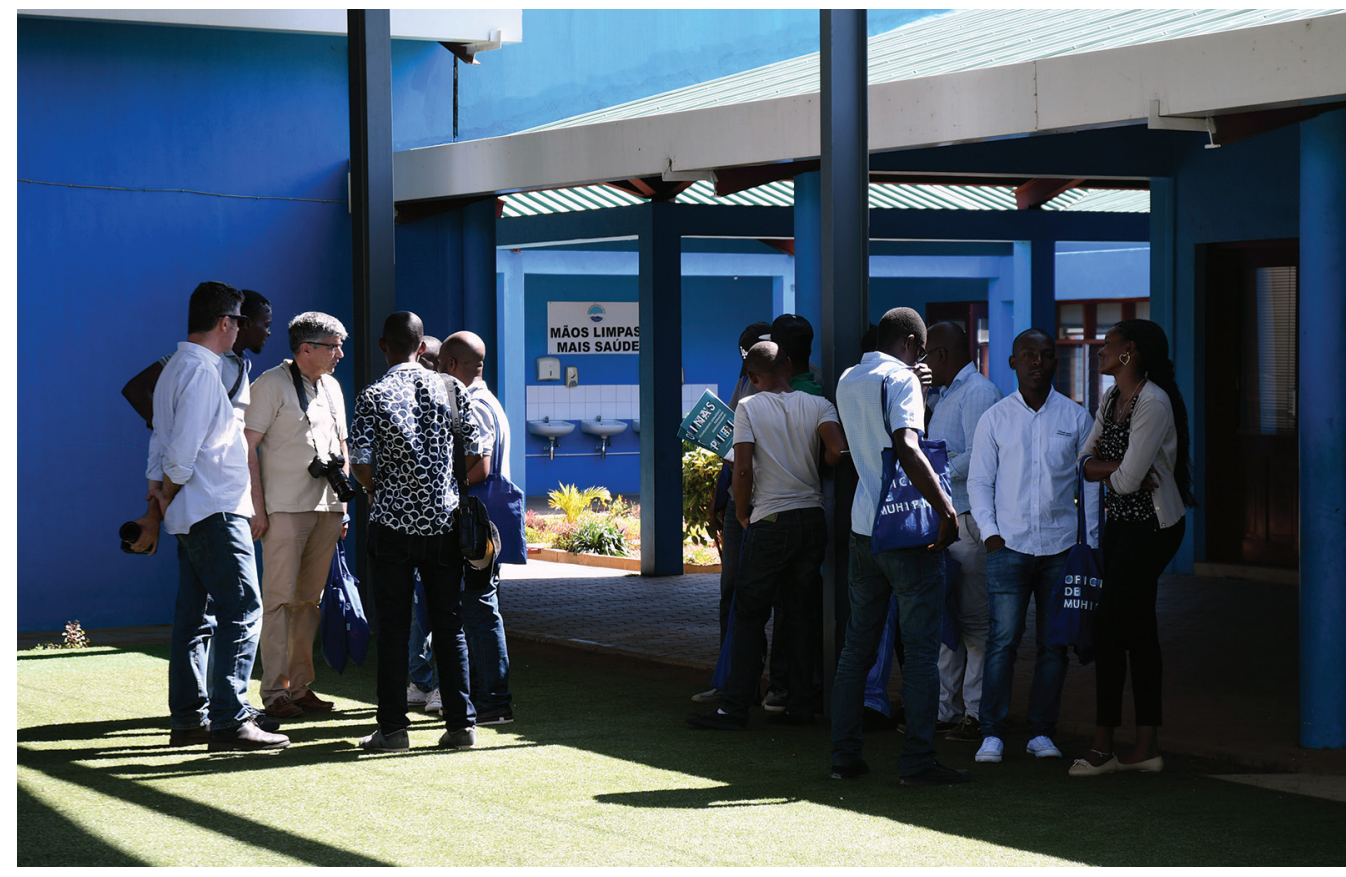

Um dos exemplos desta abordagem é o Mestrado em Património e Desenvolvimento que está a ser planeado para decorrer na llha e será oferecido com vista a poder realizar intercâmbios com instituições nacionais e internacionais dedicadas às questões do património cultural. 
A sua estrutura está a ser pensada de forma a servir também de veículo para a realização de doutoramentos por docentes da UniLúrio, oferecendo assim formação académica ao mais alto nível e, ainda, a criação de uma rede de trocas de experiências e conhecimentos que, decerto, contribuirá para o desenvolvimento do pensamento crítico e estratégico sobre as diversas vertentes das práticas patrimoniais, potenciando ações independentes, inovadoras e sustentáveis de celebração da identidade e da memória. Outro exemplo foi, precisamente, o workshop Oficinas Muhipiti: planeamento estratégico, património, desenvolvimento [Oficinas], que proporcionou um grande momento em que os estudantes foram confrontados com a dimensão interdisciplinar das matérias da Arquitetura e do Planeamento Físico e da transversalidade dos problemas no contexto do património.

Paralelamente ao alcance desse objetivo, existe a expectativa de se atingirem outros, tais como: a integração de atores locais no processo, através da participação e abordagens de aprendizagem viradas para a resolução de problemas específicos; a colocação de estudantes no centro do processo de aprendizagem; e a colocação da comunidade no processo das soluções, tendo sempre em conta a realidade local. Este processo didático enfatiza o propósito que as competências desenvolvidas pela universidade devem contemplar: não somente a aquisição de habilitações mas, acima de tudo, a união dos compromissos social e profissional. 
O Oficinas, alinhado com os programas de aprendizagem de Arquitetura e Urbanismo da UniLúrio, evidenciou que a diversidade no uso de estratégias de aprendizagem amplia a interdisciplinaridade, pela abordagem de outros campos disciplinares e pela integração de abordagens transversais de vários saberes. Consequentemente, os estudantes foram levados a confrontar-se com problemas de escala e valores diversos, à experimentação do incerto, ao estímulo da sua criatividade, à visualização diferenciada de problemas específicos. Aquele permanente contacto de contextos sócio-político-culturais, possibilitou aos estudantes experimentarem a vivência da realidade local que se inscreve nas experiências quotidianas da llha, facto que contribuiu e contribuirá consideravelmente para a preservação do seu património.

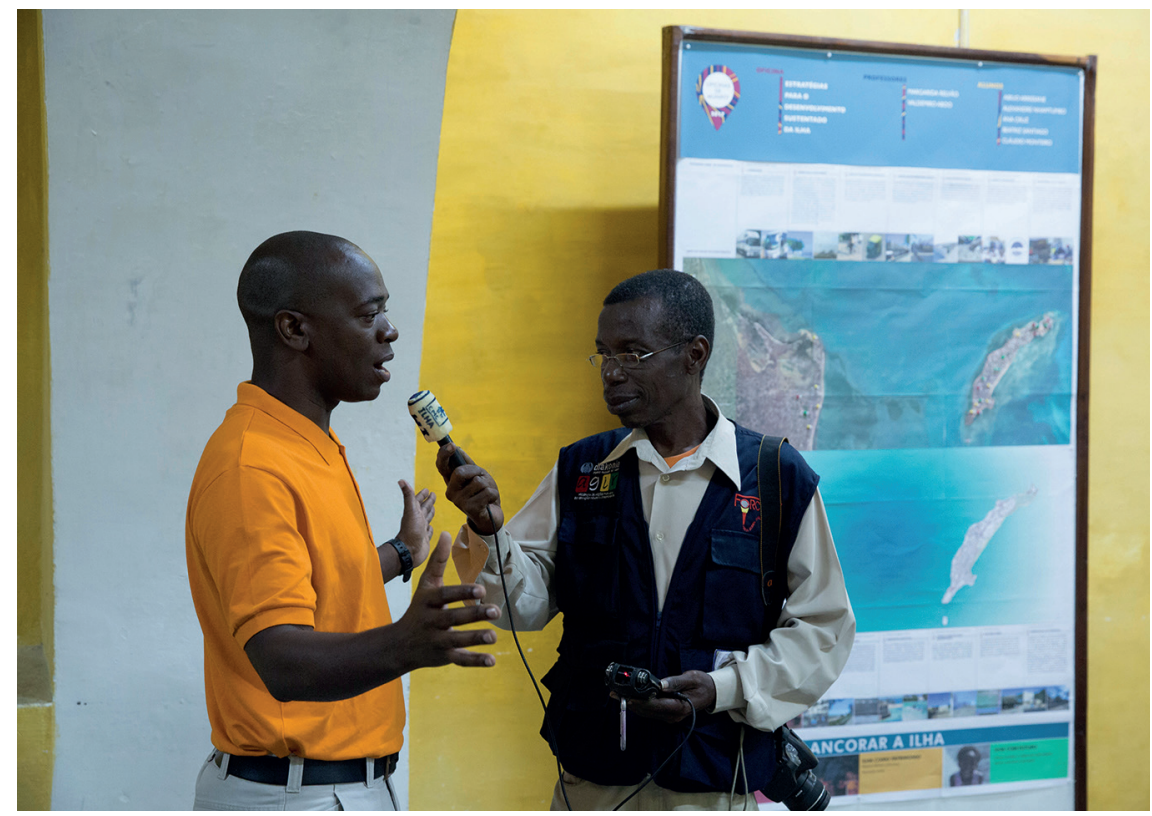

A intervenção no património impõe também um novo domínio de conhecimentos científicos que têm a ver com a sustentabilidade e a regeneração ambiental e que se adicionam, indispensavelmente, aos domínios que se prendem com os aspetos culturais, naturais, tipológicos, topológicos, topográficos, físico-químicos, antropológicos, sociológicos e dos domínios psicofisiológicos e estéticos. Pretendeu-se que o Oficinas fosse e continue a ser uma atividade inserida no conhecimento profundo 
do meio físico e cultural, pelo que se pode enraizar e estruturar uma cultura do espaço, autóctone e endógena, com base na investigação e no trabalho científico, através da FAPF, no geral, e do CEDIM, em particular.

Um dos resultados concretos e mais imediatos deste workshop será a criação, numa estrutura polinucleada, do Centro de Interpretação Muhipiti [CIM], uma plataforma integrada no CEDIM que atua na investigação, preservação e divulgação do património cultural, com base em métodos cientificamente validados, tendo em conta os tipos de património que a llha detém. A exposição preliminar dos resultados do Oficinas foi o momento zero do CIM, que em breve será substituída pela montagem do primeiro polo temático. Trata-se, pois, de um centro de interpretação dinâmico, que terá outros polos, quer na llha insular, quer no Lumbo, conforme o potencial patrimonial de cada local.

Foi assim que o Oficinas foi estruturado, de forma a responder a uma filosofia de ensino que centra no estudante a mais-valia no processo de aprendizagem, de forma a garantir o desenvolvimento sustentável, assim como melhorando e requalificando os assentamentos humanos, o desenho urbano, o restauro, a reabilitação, a manutenção de edifícios e o design de equipamentos. Os participantes foram sensibilizados para a história da realidade construída e a transformação da natureza pelo homem, para a ocupação social do espaço geográfico e mesmo dos elementos intangíveis dessas realidades, isto é, da própria personalidade do povo da llha, o seu ethos cultural.

O nosso anseio é que a experiência e resultados adquiridos ao longo do Oficinas auxilie a constituir uma ferramenta que integre os vários atores no seu processo, especificamente a Direção Nacional do Património Cultural [DNPC], o Gabinete de Conservação da Ilha de Moçambique [GACIM], e as autoridades locais, por forma a trabalhar com a comunidade e a servi-la melhor, tendo em conta o seu lema planeamento estratégico, património, desenvolvimento, segundo o qual decorreu o evento. 